\title{
Minimization of Apoptosis like Changes Developed during Cryopreservation of Buffalo Bull Sperm by Supplementing Z-LEHD-FMK (Caspase Inhibitor)
}

\author{
Jasmer Dalal $^{\text {1* }}$, Ajeet Kumar ${ }^{2}$, M. Honparkhe ${ }^{2}$, A.K. Singh ${ }^{2}$ and P.S. Brar ${ }^{2}$ \\ ${ }^{1}$ Department of Veterinary Gynaecology and Obstetrics, Lala Lajpat University of Veterinary \\ and Animal University, Hisar-125004, Haryana, India \\ ${ }^{2}$ Department of Veterinary Gynaecology and Obstetrics, Guru Angad Dev Veterinary and \\ Animal Sciences University, Ludhiana-141 004, Punjab, India \\ *Corresponding author
}

\section{A B S T R A C T}

\section{Key w ords \\ Apoptosis like changes, Buffalo bull, Caspase inhibitor, \\ Cryopreservation, Z- LEHD-FMK}

\section{Article Info}

Accepted:

08 August 2018

Available Online:

10 September 2018
Present study was undertaken to evaluate the anti-apoptotic effect of LEHD-FMK (caspase inhibitor) on buffalo bull sperm before and after semen freezing. Tris egg yolk extender was treated with Z-LEHD-FMK $(0,2,4,6,10$ and $20 \mu \mathrm{M})$ and used for extension of six aliquots of semen from each ejaculate to final concentration of 80 million sperm $/ \mathrm{ml}$. Sperm samples were analyzed for sperm motility, viability, plasma membrane integrity, mitochondrial membrane potential and PLA (Phospholipase) activity at pre-freeze and post thaw stages. There was no effect $(\mathrm{P}>0.05)$ of this caspase inhibitor on percent sperm motility, viability, plasma membrane integrity, active mitochondria and sperms with low PLA (Phospholipase) activity before semen freezing. However, Z-LEHD-FMK $(2 \mu \mathrm{M})$ treated sperm showed higher $(\mathrm{P}<0.05)$ motility with functionally intact membrane at post thaw stage as compared to control $(0 \mu \mathrm{M})$. Percent post thaw viable sperm were higher $(\mathrm{P}<0.05)$ in Z-LEHD-FMK $(2,4$ and $6 \mu \mathrm{M})$ treated semen sample as compared to control. Percent sperm with active mitochondria and low PLA activity were increased in dose dependent manner $(\mathrm{P}<0.05)$.

\section{Introduction}

To achieve optimum output from livestock, artificial insemination (AI) with frozen semen is a major breeding tool. Artificial insemination with cryopreserved semen is a widely used technique in buffalo (Singh and Balhara, 2016). However, acceptable conception rates not achieved under field conditions with frozen-thawed buffalo semen remained a challenge so far. Also, the fertility of cryopreserved semen remains poor (33\%) as compared to fresh semen (Chohan et al., 1992). This might be due to lower freezability and fertility of buffalo spermatozoa when compared with cattle spermatozoa (Singh and Pant, 2000). One important reason for poor fertility of cryopreserved semen is freezing induced apoptosis like changes inflicted in spermatozoa during cryopreservation indicated by externalization of phosphatidylserine (PS) due to higher 
phospholipase activity (Glander et al., 2002). Caspases are synthesized as non-active proenzyme (pro-caspases) which are activated by cleavage during the cascade of ordered events of apoptosis (Cohen, 1997). Apoptosislike changes has been identified by the presence of caspase 9 and caspase 3 in bovine sperm (Anzar et al., 2002), whereas increased membrane permeability and decreased mitochondrial membrane potential has been observed in equine sperm (Ferrusola et al., 2008).

Martin et al., (2004) also found that, after cryopreservation, majority of living sperm cells show low mitochondrial potential. The caspases activate DNase and are responsible for DNA fragmentation (Enari et al., 1998) and as a result, DNA damage can also initiate apoptosis (Danial and Korsmeyer, 2004). Apoptotic sperm with fragmented DNA and damaged membrane results in poor fertility rates (Erickson et al., 2015). The existence of caspase-dependent apoptotic-like mechanisms associated with mitochondrial functionality in sperm, are possibly similar to those found in somatic cells (Boise and Thompson, 1997; Ricci et al., 2003, 2004; Lakhani et al., 2006). Dalal et al., (2018) reported that Z-DEVDFMK improves post thaw percent sperm with active mitochondria and low PLA activity increases in dose dependent manner.

They also found that there was improvement in post thaw sperm viability with intact membrane following Z-DEVD-FMK (caspase inhibitor) treatment $(2,4$ and $6 \mu \mathrm{M})$. Z-LEHDFMK inhibits caspase 9 (Alicia et al., 2006) and Caspase 9 triggers a cascade of caspase activation, including caspase-3/7 that promotes cellular self-destruction (Paasch et al., 2004; Bejarano et al., 2008). So, the improvement in quality of post thaw semen could be achieved by minimizing apoptosis like changes developed during cryopreservation.

\section{Materials and Methods}

\section{Ethical approval}

The approval from the institutional animal ethics committee to carry out the present study was not required as it did not involve handling of live animals and no invasive technique was used. Semen was being collected and frozen as a routine procedure under progeny testing program of Murrah buffalo bulls.

\section{Selection of buffalo bulls}

Three breeding buffalo bull around 4 years of age maintained at bull farm, GADVASU, Punjab, India (Latitude/Longitude, $30.55^{\circ} \mathrm{N}$, $75.54^{\circ} \mathrm{E}$ ) were included in the present study. These bulls were used for routine semen collection by artificial vagina method. Bulls were maintained under loose housing system (covered area - $12 \times 10 \mathrm{ft}$ and uncovered area 25 x $10 \mathrm{ft}$ ) and standard feeding schedule along with adlib green fodder.

\section{Experimental design}

Four ejaculates, each from 3 buffalo bulls were taken in this study. Tris egg yolk extender was prepared as described by Dalal et al., (2017). Caspase inhibitor was dissolved in dimethylsulphoxide (DMSO) to prepare the stock solution (10 mM). Z-LEHD-FMK (0, 2 $\mu \mathrm{M}, 4 \mu \mathrm{M}, 6 \mu \mathrm{M}, 10 \mu \mathrm{M}$ and $20 \mu \mathrm{M})$ was mixed into the semen extender to suppress the apoptosis like changes during cryopreservation. Six aliquots from each ejaculate were extended $(80$ millions sperm $/ \mathrm{ml}$ ) with tris egg yolk extender to corresponding Z-LEHD-FMK concentrations and were frozen using standard vapour freezing method. Sperm samples were analyzed for individual motility, viability, plasma membrane integrity, mitochondrial membrane potential and status of sperm membrane phosphatidylserine through PLA 
activity at pre-freeze and post thaw stages was assessed. The individual sperm motility (\%) was assessed manually under $20 \mathrm{X}$ objective of phase contrast microscope (Nikon Eclipse $\mathrm{E}$ 200). The live sperm count (\%) was performed using Eosin-Nigrosine staining technique as per standard procedure (Blom et al., 1977). The hypo-osmotic swelling test (HOST) was performed as per standard procedure to assess the functional integrity of sperm membrane (Jeyendran et al., 1984; Dalal et al., 2016).

\section{Evaluation of mitochondrial membrane potential}

Mitochondrial membrane potential was assessed by using fluorescent dye Tetramethyl rhodamine, methyl ester (TMRM, Life Technologies; Cat\#T-668) as described by Dalal et al., (2016, 2018). Briefly, stock solution $(10 \mathrm{mM})$ of TMRM was prepared. From stock solution of TMRM, a working solution was prepared $(50 \mu \mathrm{M})$ and stored at $20^{\circ} \mathrm{C}$.After two washing with PBS at 1000 rpm for $5 \mathrm{~min}, 5 \mu \mathrm{l}$ of TMRM was added to each sperm sample and incubated at $37^{\circ} \mathrm{C}$ for $90 \mathrm{~min}$. After incubation, washing was done with PBS for $5 \mathrm{~min}$ at $37^{\circ} \mathrm{C}$ to remove the unbound dye. The sperm pellet was mixed well with $500 \mu \mathrm{l}$ of PBS. On a microslide, 10 $\mu l$ of washed sample and $8 \mu \mathrm{l}$ of ProLong Gold Antifade Mountant with DAPI (Life Technologies, Cat\# P36941) was taken and covered with coverslip. The slide was examined under upright fluorescent microscope (Nikon) with DAPI filter (420-480 $\mathrm{nm}$ ), fluorescein isothiocyanate filter (FITC) (510 - 580nm). Around 100 sperms were observed for high or low fluorescence in mid piece region as an indicator of mitochondrial membrane potential.

\section{Evaluation of sperm phospholipase activity}

Sperm phospholipid membrane was studied using BODIPY C11 fluorescent dye (4,4- difluoro-5,7-dimethyl-4-bora-3a,4a-diaza-sindacene-3-undecanoic acid (BODIPY C11 FL, Life technologies, Cat\# D 3862) as reported in previous study (Dalal et al., 2016). Briefly, $20 \mu \mathrm{M}$ of working solution prepared from stock (100mM in DMSO).

Following two washing with PBS at 1000 rpm, $30 \mu \mathrm{l}$ of BODIPY working solution was mixed to each sperm sample and incubated for $45 \mathrm{~min}$ at $37{ }^{\circ} \mathrm{C}$. After incubation, washing was done with $1 \mathrm{ml}$ of PBS at 1000 RPM for 5 minutes at $37^{\circ} \mathrm{C}$ to remove the unbound dye. The pellet was mixed well with $500 \mu \mathrm{l}$ of PBS. On a micro slide, $10 \mu$ l of sample and 8 $\mu \mathrm{l}$ of ProLong Gold AntifadeMountant with DAPI (Life Technologies, Cat\# P36941) was taken and covered with cover slip. Glass slides were examined under upright fluorescent microscope (Nikon) with DAPI filter (420-480 $\mathrm{nm})$, FITC filter (510 - 580nm). Around 100 sperms in different fields were observed and out of hundred, normal sperms without fluorescence were calculated as \% sperm with low PLA (phospholipase A1 and A2) activity.

\section{Statistical analysis}

All statistical analyses were carried at 0.05 probability level out using IBM SPSS Statistics software (IBM Corporation, USA) for windows. Data were analyzed using oneway ANOVA and comparison of means was done by Duncan Multiple Range Test (DMRT). Results are expressed as Mean \pm Standard Error of Mean. Statistical significance was set at 0.05 probability level.

\section{Results and Discussion}

In this study, Z-LEHD-FMK $(0,2,4,6,10$, and $20 \mu \mathrm{M}$ ) was used in tris egg yolk extender to reduce the apoptosis like changes in sperms. Evaluation of the pre-freeze and post-thaw semen samples parameters like percent sperm motility, viability, plasma membrane integrity, 
mitochondrial membrane potential, and sperm PLA activity status is shown in Table 1.

\section{Sperm Motility}

There was no effect of Z-LEHD-FMK $(\mathrm{P}>0.05)$ on percent motility before freezing. However, percent post thaw motility in $2 \mu \mathrm{M}$ (55.45 \pm 3.78$)$ concentration of Z-LEHD-FMK was higher $(\mathrm{P}<0.05)$ than other treatments $(4$, $6,10$ and $20 \mu \mathrm{M})$ and control (45.54 \pm 3.34$)$. The mechanisms of inducing apoptosis by different caspases are more complex and many factors may be involved (Sule et al., 2013). However, in a study Dalal et al., (2018) did not find any significant $(\mathrm{P}>0.05)$ effect on percent motility following Z-DEVD-FMK treatment. Furthermore, Chen et al., (2006) reported an inverse relationship between sperm motility and apoptosis in human sperms.

\section{Sperm viability}

In the present study, the percent viable sperms count was similar $(\mathrm{P}>0.05)$ in pre-freeze sperms both in treated and control group. However, the percent viable sperms count at post thaw stage was higher $(\mathrm{P}<0.05)$ in $2 \mu \mathrm{M}$ concentration $(86.36 \pm 3.67)$ of Z-LEHD-FMK as compared to other $4(66.66 \pm 6.32), 6$ (76.78 \pm 5.78$), 10(52.46 \pm 7.31)$ and $20 \mu \mathrm{M}$ $(48.57 \pm 5.65)$ and control (48.78 \pm 7.34$)$.

Percent viable sperms count in post-thaw samples was similar $(\mathrm{P}>0.05)$ between $\mathrm{Z}$ LEHD-FMK treated $(10,20 \mu \mathrm{M})$ and control samples. But these showed lesser viable sperm count as compared to 2,4 and $6 \mu \mathrm{M}$ treatments. In a previous study, Z-DEVDFMK (2 and $4 \mu \mathrm{M})$ treatment also improved $(\mathrm{P}<0.05)$ the sperm viability (Dalal et al., 2018). These caspase inhibitors inhibited the caspases that share some of the apoptosis pathways and more or less oppose the apoptosis.

\section{Hypo osmotic swelling test (HOST)}

Before freezing, there were no difference $(\mathrm{P}>0.05)$ in percent sperms with intact plasma membrane between control and Z-LEHDFMK $(2,4,6,10$ and $20 \mu \mathrm{M})$ as assessed through HOST. Host reactive sperms in post thaw samples were higher $(\mathrm{P}<0.05)$ in $2 \mu \mathrm{M}$ $(66.64 \pm 4.89)$ as compared to other concentration of Z-LEHD-FMK like $4 \mu \mathrm{M}$

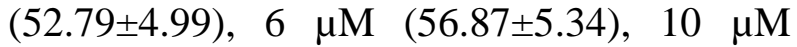
$(44.56 \pm 5.33) 20 \mu \mathrm{M}(50.31 \pm 6.66)$ and control (51.5 \pm 3.73$)$.

So, Z-LEHD-FMK protects the plasma membrane in lower concentrations. In previous study (Dalal et al., 2018), Z-DEVDFMK treatment also reported to protect the plasma membrane $(\mathrm{P}<0.05)$.

\section{Mitochondrial status}

The percent active mitochondria were similar $(\mathrm{P}>0.05)$ in Z-LEHD-FMK ( $(2,4,6,10$ and $20 \mu \mathrm{M})$ treated and control before freezing. However, in post thaw sperm, percent active mitochondria were higher $(\mathrm{P}<0.05)$ in $6 \mu \mathrm{M}$ (75.56 \pm 3.45$), 10 \mu \mathrm{M}(78.11 \pm 2.27)$ and $20 \mu \mathrm{M}$ (82.40 \pm 2.56$)$ concentrations of Z-LEHD-FMK as compared to control $(65.6 \pm 3.45)$.

The percent active mitochondria in post thaw samples did not differ $(\mathrm{P}>0.05)$ in2 $\mu \mathrm{M}$ (67.12 \pm 4.12$), 4 \mu \mathrm{M}(70.34 \pm 4.44)$ and control $(60.66 \pm 3.89)$.

Also, percent active mitochondria in $20 \mu \mathrm{M}$ were higher $(\mathrm{P}<0.05)$ as compared to and 10 $\mu \mathrm{M}(77.5 \pm 1.45)$ doses. Previously, Dalal et al., (2018) also recorded improvement in maintenance of mitochondrial potential with Z-DEVD-FMK following cryopreservation. Hence, Z-LEHD-FMK help in maintaining mitochondrial membrane potential of spermatozoa in dose dependent manner following cryopreservation of semen. 
Table.1 Effects of different treatments of Z-LEHD-FMK on various sperm parameters at prefreeze and post thaw stage

\begin{tabular}{|c|c|c|c|c|c|c|c|c|c|c|c|c|}
\hline \multirow{2}{*}{ 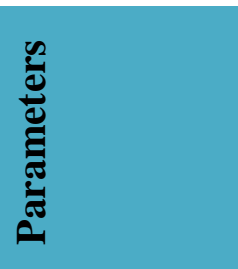 } & \multicolumn{6}{|c|}{ Pre-freeze } & \multicolumn{6}{|c|}{ Post thaw } \\
\hline & 它 & $\sum_{N}$ & $\sum_{\nabla}$ & $\sum_{0}^{1}$ & $\sum^{\infty}$ & 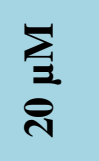 & 它 & $\sum_{N}$ & $\sum_{\nabla}$ & $\sum_{0}^{1}$ & $\sum_{i}$ & $\sum_{i}^{i}$ \\
\hline Motility (\%) & $\begin{array}{c}80.2 \\
8 \pm 8 \\
.77\end{array}$ & $\begin{array}{l}85.6 \\
7 \pm 7 \\
.89\end{array}$ & $\begin{array}{c}85.2 \\
3 \pm 6 \\
.99\end{array}$ & $\begin{array}{l}85.5 \\
9 \pm 5 \\
.55\end{array}$ & $\begin{array}{c}85.2 \\
9 \pm 5 \\
.81\end{array}$ & $\begin{array}{l}80.6 \\
7 \pm 7 \\
.45\end{array}$ & $\begin{array}{c}45.5 \\
4 \pm 3 \\
34^{\mathrm{a}}\end{array}$ & $\begin{array}{c}55.4 \\
5 \pm 3 \\
78^{\mathrm{b}}\end{array}$ & $\begin{array}{c}45.9 \\
7 \pm 4 \\
65^{\mathrm{a}}\end{array}$ & $\begin{array}{c}45.5 \\
6 \pm 4 \\
67^{\mathrm{a}}\end{array}$ & $\begin{array}{l}50.3 \\
4 \pm 4 . \\
61^{\mathrm{ab}}\end{array}$ & $\begin{array}{c}47.6 \\
6 \pm 4 \\
56^{\mathrm{a}}\end{array}$ \\
\hline $\begin{array}{l}\text { Live sperm } \\
\qquad(\%)\end{array}$ & $\begin{array}{c}80.6 \\
7 \pm 5 \\
.22\end{array}$ & $\begin{array}{c}82.0 \\
\pm 3 \\
56\end{array}$ & $\begin{array}{c}74.4 \\
5 \pm 8 \\
.61\end{array}$ & $\begin{array}{c}78.6 \\
7 \pm 8 \\
.32\end{array}$ & $\begin{array}{c}80.8 \\
7 \pm 6 \\
.55\end{array}$ & $\begin{array}{c}74.6 \\
2 \pm 4 \\
.98\end{array}$ & $\begin{array}{c}48.7 \\
8 \pm 7 \\
34^{\mathrm{a}}\end{array}$ & $\begin{array}{l}86.3 \\
6 \pm 3 \\
67^{c}\end{array}$ & $\begin{array}{l}66.6 \\
6 \pm 6 . \\
32^{b}\end{array}$ & $\begin{array}{l}76.7 \\
8 \pm 5 . \\
78^{\mathrm{bc}}\end{array}$ & $\begin{array}{c}52.4 \\
6 \pm 7 \\
31^{\mathrm{a}}\end{array}$ & $\begin{array}{l}48.5 \\
7 \pm 5 \\
65^{\mathrm{a}}\end{array}$ \\
\hline $\begin{array}{c}\text { Sperm with } \\
\text { intact } \\
\operatorname{PM}(\%)\end{array}$ & $\begin{array}{c}74.5 \\
6 \pm 5 \\
.88\end{array}$ & $\begin{array}{c}78.4 \\
8 \pm 6 \\
.45\end{array}$ & $\begin{array}{l}66.1 \\
9 \pm 5 \\
.47\end{array}$ & $\begin{array}{c}68.5 \\
2 \pm 6 \\
.88\end{array}$ & $\begin{array}{c}64.4 \\
5 \pm 4 \\
.87\end{array}$ & $\begin{array}{l}68.4 \\
4 \pm 3 \\
.67\end{array}$ & $\begin{array}{r}51.5 \\
\pm 3.7 \\
3^{a}\end{array}$ & $\begin{array}{l}66.6 \\
4 \pm 4 \\
89^{b}\end{array}$ & $\begin{array}{c}52.7 \\
9 \pm 4 . \\
99^{a}\end{array}$ & $\begin{array}{l}56.8 \\
7 \pm 5 \\
34^{\mathrm{a}}\end{array}$ & $\begin{array}{c}44.5 \\
6 \pm 5 . \\
33^{\mathrm{a}}\end{array}$ & $\begin{array}{l}50.3 \\
1 \pm 6 . \\
66^{\mathrm{a}}\end{array}$ \\
\hline $\begin{array}{l}\text { Active MT* } \\
\qquad(\%)\end{array}$ & $\begin{array}{c}78.1 \\
1 \pm 2 \\
.35\end{array}$ & $\begin{array}{l}80.6 \\
7 \pm 2 \\
.89\end{array}$ & $\begin{array}{c}82.6 \\
6 \pm 5 \\
.31\end{array}$ & $\begin{array}{c}83.5 \\
7 \pm 3 \\
.71\end{array}$ & $\begin{array}{c}85.4 \\
5 \pm 4 \\
.66\end{array}$ & $\begin{array}{c}84.6 \\
\pm 2 \\
56\end{array}$ & $\begin{array}{c}60.6 \\
6 \pm 3 \\
89^{a}\end{array}$ & $\begin{array}{l}67.1 \\
2 \pm 4 \\
12^{\mathrm{ab}}\end{array}$ & $\begin{array}{l}70.3 \\
4 \pm 4 . \\
44^{\text {ab }}\end{array}$ & $\begin{array}{c}75.5 \\
6 \pm 3 \\
45^{b}\end{array}$ & $\begin{array}{l}78.1 \\
1 \pm 2 \\
27^{b c}\end{array}$ & $\begin{array}{l}82.4 \\
0 \pm 2 . \\
56^{c}\end{array}$ \\
\hline $\begin{array}{l}\text { Sperm with } \\
\text { low PLA } \\
\text { activity }(\%)\end{array}$ & $\begin{array}{c}75.8 \\
9 \pm 3 \\
.67\end{array}$ & $\begin{array}{c}75.2 \\
1 \pm 4 \\
.58\end{array}$ & $\begin{array}{c}83.3 \\
3 \pm 4 \\
.37\end{array}$ & $\begin{array}{c}84.2 \\
1 \pm 3 \\
.78\end{array}$ & $\begin{array}{c}82.6 \\
7 \pm 5 \\
.12\end{array}$ & $\begin{array}{l}81.5 \\
\pm 2 \\
66\end{array}$ & $\begin{array}{l}60.2 \\
3 \pm 3 \\
23^{\mathrm{a}}\end{array}$ & $\begin{array}{l}70.3 \\
4 \pm 3 \\
36^{b}\end{array}$ & $\begin{array}{l}74.5 \\
5 \pm 2 . \\
48^{b}\end{array}$ & $\begin{array}{c}73.7 \\
6 \pm 3 \\
12^{b}\end{array}$ & $\begin{array}{l}78.8 \\
7 \pm 4 \\
23^{\mathrm{bc}}\end{array}$ & $\begin{array}{l}82.5 \\
5 \pm 4 . \\
11^{c}\end{array}$ \\
\hline
\end{tabular}

Values marked with dissimilar superscript differ significantly $(\mathrm{P}<0.05)$ within a row. PM and MT refers to plasma membrane and mitochondria of sperms, respectively.

\section{PLA activity}

Before freezing, there were no difference $(\mathrm{P}<$ $0.05)$ between control and Z-LEHD-FMK (2, $4,6,10$ and $20 \mu \mathrm{M})$ treated samples in terms of percent sperms with low PLA activity. However, the percent sperms with low PLA activity in post thaw samples were higher $(\mathrm{P}<$ $0.05)$ in $2 \mu \mathrm{M}(74.11 \pm 4.75), 4 \mu \mathrm{M}(78.55 \pm$ 3.11), $6 \mu \mathrm{M}(73.36 \pm 5.32), 10 \mu \mathrm{M}(75.45 \pm$ 6.56) and $20 \quad \mu \mathrm{M} \quad(80.51 \quad \pm \quad 5.55)$ concentrations of Z-LEHD-FMK as compared to control $(60.87 \pm 4.68)$. The percent sperms with low PLA activity in post thaw samples were higher $(\mathrm{P}<0.05)$ in 10 and $20 \mu \mathrm{M}$ of $\mathrm{Z}$ LEHD-FMK as compared to lower concentrations. Our study indicated that ZLEHD-FMK supplementation has protective effect against apoptosis like changes in spermatozoa during cryopreservation as reported previously by Dalal et al., (2018) with the use of Z-DEVD-FMK.

To the best of our knowledge, this is the first report on use of Z-LEHD-FMK to minimize apoptosis like changes in buffalo sperm induced during cryopreservation. Cryopreservation induce increase in caspase activation in human sperm positive for active Caspase-3 (32.6\%) followed by active Caspase-8 sperm (30.5\%), active Caspase-9 sperm (22.2\%) and active Caspase-11 sperm $(15.5 \%)$ underlining the central role of the effector caspase-3 (Paasch et al., 2004). The increase in caspase activation is dependent on the sperm preparation and cryopreservation protocol (Grunewald et al., 2005). Cryopreservation has been reported to activate caspase- 3 and -9 in humans (Paasch et al., 2004; Bejarano et al., 2008) and in boar 
sperms (Van Gurp et al., 2003). Caspase activation following the cryopreservation and thawing process is also reported in cattle (Martin et al., 2004; 2007) and equine spermatozoa (Brum et al., 2008; Ferrusola et al., 2008). It is well known fact that during apoptosis, mitochondrial pores open causing releasing of pre-apoptotic proteins like CytochromeC (an electron transport chain component) from inner membranous space to outside which activates caspase 9 in bovines (Reed 1997a). Bejarano et al., (2008) reported that Z-LEHD-FMK abolished $\mathrm{H}_{2} \mathrm{O}_{2}$-induced phosphatidylserine exposure. Similarly, they also found that progesterone induced PS externalization was dependent on caspase-9 activation. However, progesterone present in substantial amounts in egg yolk is being routinely used to prepare semen extenders. Bertin et al., (2013) reported that progesterone concentrations in egg yolk as $1823.71 \pm 64.24 \mathrm{ng} / \mathrm{g}$. As $20 \%$ egg yolk is used in semen extender, so progesterone of egg yolk in semen extender might induced PS externalization.

Also, Cytochrome $\mathrm{C}$ released due to mitochondrial damage does not activate procaspase-8, but, is known to primarily activate procaspase-9 (Peter et al., 2003). Caspase 9 triggers a cascade of caspase activation, including caspase-3/7 that promotes cellular self-destruction (Paasch et al., 2004; Bejarano et al., 2008). Caspase 3 and 7 are the executioner proteome of apoptosis (Vilmont et al., 2012). It has been reported that Z-LEHD-FMK selectively inhibits the caspase 9 (Alicia et al., 2006).

Procaspase-9 was reported in cattle bull sperm, but procaspase- 3 and -8 were absent and cryopreservation had been reported to activate caspase-9 in cattle bull sperm (Martin et al., 2007). Our study indicates that lower concentration $(2 \mu \mathrm{M})$ of Z-LEHD-FMK improves the sperm motility, viability and sperm membrane integrity whereas percent sperm count with high mitochondrial potential and low PLA activity of sperm were increased in dose dependent manner. Furthermore, additional depth studies will be required to assess the other properties of caspase inhibitors. It has been reported that the addition of caspase inhibitors to the cryopreservation medium failed to improve the acrosome and plasma membrane integrity of frozen-thawed of ram (Marti et al., 2008), $\operatorname{dog}($ Peter and Linde-Forsberg, 2003) and stallion sperms (Peter et al., 2005). These differences from our study may be due to the species variationor differences in doses of supplementation. Peter et al., (2005) also suggested that a higher or lower level of caspase doses with different timings of treatment may produce the desired effects.

In conclusion, the Z-LEHD-FMK improves spermmotility, viability and plasma membrane integrity in lower concentrations together with maintenance of mitochondrial potential with low PLA activity in post thaw semen samples in a dose dependent manner. It implies that apoptosis like changes developed during cryopreservation and Z-LEHD-FMK helps to counteract these apoptosis-like changes in sperms.

\section{Conflict of interest statement}

The authors declare no conflict of interests (financial or nonfinancial) with any organization or entity.

\section{Acknowledgments}

This work was supported by the Department of Biotechnology (DBT), Government of India; vide BT/PR3596/AAQ/01/483/2011 under the project "Improvement in fertilizability of cryopreserved buffalo bull semen by minimizing cryo-capacitation and apoptosis-like changes." 


\section{References}

Alicia, B. B., Sexton, K. B. and Bogyo, M. (2006). Commonly used caspase inhibitors designed based on substrate specificity profiles lack selectivity. Cell research. 16: 961-63.

Anzar, M., Liwei, He., Mary, M., Buhr, T.G. and Kroetsch, P. K.P. (2002). Sperm apoptosis in fresh and cryopreserved bull semen detected by flow cytometry and its relationship with fertility. Biol. Reprod., 66:354-60.

Bejarano, I., Lozano, G.M., Ortiz, A., Garcia, J.F., Paredes, S.D., Rodri'guez, A.B. and Pariente, J.A. (2008). Caspase-3 activation in human spermatozoa in response to hydrogen peroxide and progesterone. Fertil. Steril., 90:1340 1347.

Bertin, A., Chanson, M., Delaveau, J., Mercerand, F., Möstl, E. and Calandreau L. (2013). Moderate heat challenge increased yolk, steroid hormones and shaped offspring growth and behavior in chickens. PLOS ONE 8(2): e57670.

Blom, E. (1977). The evaluation of bull semen with special reference to its use in artificial insemination. Anim. Breed. Abstr., 19: 648.

Boise, L.H. and Thompson, C.B. (1997). Bcl$\mathrm{x}(\mathrm{L})$ can inhibit apoptosis in cells that have undergone Fas-induced protease activation. Proc. Natl. Acad. Sci., USA; 94:3759-3764.

Brum, A.M, Sabeur, K. and Ball, B.A. (2008). Apoptotic-like changes in equine spermatozoa separated by densitygradient centrifugation or after cryopreservation.

Theriogenology.69:1041-1055.

Chohan, K.R., Iqbal, J., Asghar, A.A. and Chaudhry, M.A. (1992). Fertility of liquid and frozen semen in Nili Ravi buffaloes. Pak. Vet. J., 12:4-5.
Cohen, G. M. (1997). Caspases: the executioners of apoptosis. Biochem. J., 326: 1-16.

Dalal, J., Kumar, A., Honparkhe, M., Deka, D. and Singh, N. (2016). Minimization of apoptosis-like changes in cryopreserved buffalo bull sperm by supplementing extender with Bcl-2 protein.Vet. World., 9(5): 432-436.

Dalal, J., Kumar, A., Honparkhe, M., Singh, Singh A.K. and Brar, P.S. (2018). Minimization of Apoptosis like Changes by Supplementing Z-DEVDFMK (CASPASE inhibitor) during Cryopreservation of Buffalo Bull Semen. Int.J.Curr.Microbiol.App.Sci., 7(07):3333-3340.

Dalal, J., Kumar, A., Honparkhe, M., Singhal, S. and Singh, N. (2016). Comparison of three programmable freezing protocols for the cryopreservation of buffalo bull semen.Ind. J. Ani. Reprod., 37 (2):5455.

Dalal, J., Kumar, A., Kumar, P., Honparkhe, M., Malik, V.S., Singhal, S., Kaur, S. and Brar, P.S. (2018). Improvement in cryosurvival of buffalo bull (Bubalus bubalis) sperm by altering freezing rate within critical temperature range. Asian. Pac. J. Reprod., 7(2): 72-78.

Danial, N.N. and Korsmeyer S J. (2004). Cell death: critical control points.Cell. 11: 205-19.

Enari. M., Sakahira, H., Yokoyama, H., Okawa, K., Iwamatsu, and Nagata, S. (1998). A caspase activated DNase that degrades DNA during apoptosis, and its inhibitor ICAD. Nature. 391: 43-50.

Erickson, L., Kroetsch, T. and Anzar, M. (2015). Relationship between sperm apoptosis and bull fertility: in vivo and in vitro studies. Reprod. Fertil. Dev., 28(9): 1369-1375. doi: 10.1071/ RD14417

Ferrusola, C.O., Galan, Y.S., Fernandez, E.V., Bolanos, J.M.G., Muriel, A., Fernandez, 
L.G., Tapia, J.A. and Pena, F.J. (2008). Detection of "apoptosis-like" Changes during the cryopreservation process in equine sperm. J. Androl., 29:213-21.

Glander, H.J., Schiller, J., Süss, R., Paasch, U., Grunewald, S. andArnhold, J. (2002). Deterioration of spermatozoal plasma membrane is associated with an increase of sperm lysophosphatidylcholines. Andrologia. 34(6): 360-6.

Grunewald, S., Paasch, U., Wuendrich, K. andGlander, H.J. (2005). Sperm caspases become more activated in infertility patients than in healthy donors during cryopreservation. Arch.Androl., 51:449-460.

Jeyendran, R.S., Vander-Ven, H.H., PerezPelaez, M., Crabo, B.G. and Zanevld, L.J.D. (1984). Development of an assay to assess the functional integrity of the human sperm membrane and its relationship to other semen characters. J. Reprod. Fertil., 70: 219-28.

Lakhani., S.A., Masud, A., Kuida, K., Porter, G.A Jr., Booth, C.J., Mehal, W.Z., Inayat, I. and Flavell, R.A. (2006). Caspases 3 and 7: key mediators of mitochondrial events of apoptosis. Science. 311:847-851.

Marti, E., Perez-Pe R. and Colas, C. (2008). Study of apoptosis-related markers in ram spermatozoa. Anim. Reprod. Sci., 106:113-132.

Martin, G., Cagnon, N. andSabido, O. (2007). Kinetics of occurrence of some features of apoptosis during the cryopreservation process of bovine spermatozoa. Hum. Reprod., 22: 380-88.

Martin, G., Sabido, O., Durand, P. and Levy1, R. (2004). Cryopreservation induces an apoptosis-like mechanism in bull sperm. biol. Reprod., 71:28-37.

Ortega-Ferrusola., C., Sotillo-Gala'n, Y., Varela-Fernández, E., GallardoBolaños, J.M., Muriel, A. and
Gonza'lez-Ferna'ndez.

(2008)

Detection of "apoptosis-like" changes during the cryopreservation process in equine sperm. J.Androl., 29: 213-21.

Paasch, U., Sharma, R.K., Gupta, A.K., Grunewald, S., Mascha, E.J., Thomas. A.J., Glander, J.H. J. and Agarwal, A. (2004). Cryopreservation and thawing is associated with varying extent of activation of apoptotic machinery in subsets of ejaculated human spermatozoa. Biol. Reprod., 71:182837.

Peter, A.T. and Linde-Forsberg, C. (2003). Efficacy of the anticaspase agent zVAD-fmk on post-thaw viability of canine spermatozoa. Theriogenology. 59:1525-1532.

Peter, A.T., Colenbrander, B. and Gadella, B.M. (2005). Effect of caspase inhibitors on the post-thaw motility, and integrity of acrosome and plasma membrane of cryopreserved equine spermatozoa. Indian. J. Exp. Biol., 43:483-487.

Ricci, J.E., Gottlieb, R.A. and Green, D.R. (2003). Caspase-mediated loss of mitochondrial function and generation of reactive oxygen species during apoptosis. J. Cell. Biol., 160:65-75.

Ricci, J.E., Munoz-Pinedo, C., Fitzgerald, P., Bailly-Maitre, B., Perkins, G.A., Yadava, N., Scheffler, I.E., Ellisman, M.H. and Green, D.R. (2004). Disruption of mitochondrial function during apoptosis is mediated by caspase cleavage of the p75 subunit of complex I of the electron transport chain. Cell. 117:773-786.

Singh, M. and H.C. Pant. (2000). Effect of post-thawincubation on semen quality of buffalobulls-comparison with cattle. Buffalo Bull., (19): 51-54.

Sule, D., Mason, M.C., Aruna, G., Lauren, B., Abdullah, K., John, S., Dennis, R. and Erdogan, M. (2013). Interrelationships 
between apoptosis and fertility in bull sperm. J. Reprod. Dev., (59): 18-26.

Van Gurp, M., Festjens, N., van Loo, G., Saelens, $X$. and Vandenabeele, $P$. (2003). Mitochondrial intermembrane proteins in cell death. Biochem. Biophys. Res. Commun., 304:487-97.
Vilmont, V., Tourneur, L. and Chiocchia, G. (2012). FasF associated death domain protein and adenosine partnership: fad. In: R A. Rheumatology (Oxford) 51: 964-75.

\section{How to cite this article:}

Jasmer Dalal, Ajeet Kumar, M. Honparkhe, A.K. Singh and Brar, P.S. 2018. Minimization of Apoptosis like Changes Developed during Cryopreservation of Buffalo Bull Sperm by Supplementing Z-LEHD-FMK (Caspase Inhibitor). Int.J.Curr.Microbiol.App.Sci. 7(09): 10761084. doi: https://doi.org/10.20546/ijcmas.2018.709.128 